Each of the eight papers is illustrated with carefully captioned photomicrographs, from which those in this article have been reproduced. Nakava's technique of photographing snowflakes is exquisite and far superior to any that I have seen. While following the general method employed by W. A. Bentley, he gains both in accuracy and, incidentally, in artistic effect by not trimming the margins of the flakes, and by reproducing the photographs on a light instead of a dark background. Remarkable and beautiful as was Bentley's work ${ }^{6}$, its re-publication has lost in scientific value by the omission of the degree of magnification and of meteorological conditions obtaining at the time of the collection of the flakes. Nakaya's work is a continuation of and improvement on Bentley's.

What we must now hope is that Prof. Nakaya will continue his researches. Some of his results are only tentative, and some of his later work admittedly negatives his earlier, so that a summarized version of the results of the whole eight papers in the light of his most recent experiments would add greatly to their value. Be all that as it may, there is no doubt that the work in total adds very considerably to our knowledge of the nature of falling snow.

G. Seligman.

\footnotetext{
1"Snow Structure and Ski Fields", p. 36 (Macmillan, 1936).

2 ibid., p. 40.

3 Nakaya has since written that this form is a modiflcation of the hollow cup crystal.

4 Studien über die Nebelfrostablagerungen auf dem Partetjakko. Naturwissenschaftliche Untersuchungen des Sarekgebirges in Schwedisch-Lappland", 2, Abt. 1, Meteorologie und Geophysik, ief. 1, 1-76. (Stockholm, 1923.)

${ }^{5}$ According to Schmidt, W., Sitz. Ber. Wien, 118, 71 (1909).

6 "Snow Crystals", by W. A. Bentley and W. J. Humphreys (McGraw. Hill Book Co., Inc., New York, 1931).
}

\title{
Mendel, Morgan and Genetics
}

\section{By Prof. E. W. MacBride, F.R.S.}

$\mathrm{T}$ HE modern science of genetics has acquired an enormous extension. As Prof. McDougall has said, it has swept over North America like a whirlwind. Everywhere chairs in genetics have been established, nay more, in some places special chairs in 'Drosophily' devoted to the exclusive study of this type-animal. Its votaries claim that in this science are to be found the solution not only of all the questions of the origin, propagation and improvement of our domesticated animals and cultivated plants, but also of the origin of species and evolution. Nevertheless, as time went on, the fair prospects of the science darkened. The hope of getting an unlimited number of new and valuable varieties was disappointed. As one of the professors of this science has ruefully expressed it, "The qualities that mendelize are not those which are of any value to farmers and those which farmers value do not mendelize." Anyone who reads, as I do, the minutes of the Agricultural Research Council, which contain an account of all the agricultural experiments seeking Government aid which are being carried out in Great Britain, must be struck with the fact that Mendelism is scarcely ever mentioned.

If 'genetics' be defined as the study of heredity free from presuppositions, then this study will be readily acknowledged to be a most important branch of the science of biology. But in practice, 'genetics' means the interpretation of hereditary phenomena according to fixed rules or postulates which were worked out by the late Dr. W. Bateson in Great Britain and by Prof. T. H. Morgan in the United States.
The discovery by Mendel of the facts of alternative inheritance and their rediscovery by Bateson and Correns were hailed as the greatest advance in biology since the publication of "The Origin of Species". The first question to be asked is whether what Bateson called 'unit-factors' and which are more frequently termed 'genes' have really the significance which has been attached to them. Mendel himself did not suppose that the phenomena of alternative inheritance covered more than a small part of heredity, but the persistent effort of all subsequent geneticists has been to crush all cases of heredity into this mould.

Bateson, who had the advantage of a broad education in biology at a time when in fame and brilliance the Cambridge School was at its zenith, really did most, especially in his later years, to clarify the position. He showed that alternative characters or 'allelomorphs', as he termed them, were related to each other in such a way that the dominant was characterized by something which was absent in the recessive. This definition was afterwards altered to stronger and weaker expressions of the same character. The classical experiments on peas will illustrate this point clearly. Yellow peas are dominant to green peas. But all peas when immature are green; the yellow pea on ripening transforms its chlorophyll into etiolin whereas the green pea stops short in its development. Similarly, round peas are dominant over wrinkled peas. Again, all young peas are round : in dominants, the round form is retained 
owing to the transformation of an adequate amount of sugar into starch, but in the wrinkled peas less starch is found and an amount of sugary solution remains, and when this dries up in ripening, a shrinkage occurs which leads to a wrinkled seedcoat. When, therefore, two parents mate and each has some of the specific characters in their dominant form, this merely means that some of the specific characters are more strongly marked in the mother and some in the father. It is sometimes possible to mate two forms such as a regular sea-urchin and a heart-urchin which have been distinct for millions of years, and in the offspring the paternal influence may sometimes show and at other times the maternal. In picking out a recessive as a new variety to be propagated, we are really selecting a weakened form. As he grew older, Bateson became more and more convinced that an increasing number of cases of inheritance could not be brought under the Mendelian laws at all.

But the great extension which 'genetics' has attained in recent years is undoubtedly due to Morgan. He has, with a certain amount of justice, been termed the founder of the science of genetics. As is well known, in the ripening of the nuclei of the sexual cells a stage occurs which is known as 'meiosis'. In this stage, the paternal and maternal chromosomes approach each other in pairs and appear to come into actual contact with one another; they then separate, and half go to one pole of the nucleus and half to another. The nucleus then divides and the number of chromosomes is thus reduced to one half: the sexual cell is now ready to unite with another one with a similarly reduced number of chromosomes and so in the zygote the full number is restored. Now, according to Morgan, when meiosis takes place, the pairing chromosomes are very long and spirally twisted, and Morgan assumes that they break and exchange portions of their substance. If, then, the Mendelizing factors are based on discrete material particles situated in definite positions in the chromosome, the transference of dominant characters from one partner to another could be accounted for. Further, if two factors were situated near each other in the chromosome, it might be expected that the break would occur in such a manner that the separated piece would contain both factors. In this way, the association of two factors in inheritance was explained. The farther apart the position of the factors in the chromosome the more seldom would they be included in the same broken-off piece, and by the relative frequency of their association enthusiasts have attempted to construct a map of the chromosome and even to reckon the distance of two factors (in 'centimorgans') from each other.
It may appear to some readers that this whole theory is a rather risky castle of cards to erect on the basis of certain very dubious assumptions; and it is one of the main purposes of this article to show that these assumptions are incorrect, and consequently the whole chromosome theory falls to the ground. The question which we wish to put is whether the appearances of two long chromosomes slightly curved around one another are really an expression of meiosis or not. In my opinion, this question has been definitely decided in the negative by two researches, namely, "The Spermatogenesis of Lepidosiren paradoxa" (Quart. $J$. Micro. Sci., 57, 1911) by Dr. W. E. Agar of Glasgow (now professor of zoology in the University of Melbourne) and "The Meiotic Phase in Vertebrates" by Prof. C. E. Walker of the Department of Cytology in the University of Liverpool. The latter research was published in two papers, namely,

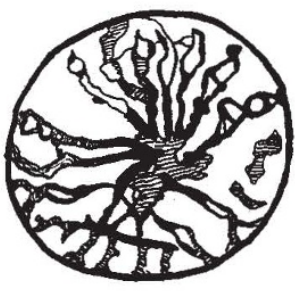

Fig. 1.

THE 'FIRST' MEIOSIS OF LEPIDOSIREN

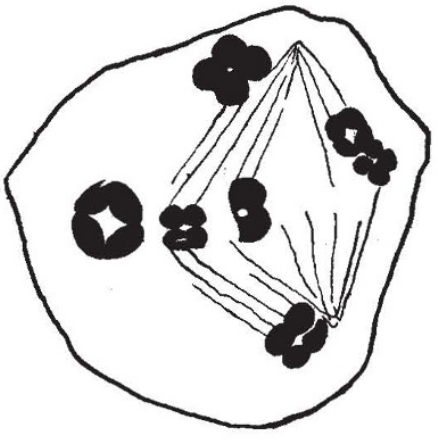

Fig. 2.

THE 'SECOND' MEIOSIS OF LEPIDOSIREN
"The Meiotic Phase in Triton vulgaris" (Proc. Roy. Soc., B, 98; 1925) and "The Meiotic Phase in Certain Mammals" (Proc. Roy. Soc. B, 99 ; 1926).

Agar's researches were suggested to him by his teacher, Prof. Graham Kerr. This was a stroke of genius on Prof. Kerr's part. He argued thus : if so much importance is attached to minute details in the ripening process of the nucleus, would it not be essential to study them in the largest nuclei available? He knew well that the nuclei of the sexual cells of the testes in Lepidosiren were gigantic, so large indeed that it is impossible to include one of them as a single microtome section.

Agar found the ripening process beginning with the apparent apposition of two long chromosomes in the manner described by Morgan, and as he was at the time an orthodox geneticist, he interpreted it in the same manner. But to his amazement, when the putative meiotic partners separated, they shortened and condensed and the same partners then underwent a second meiosis during the ripening of the same nucleus 1 The so-called first meiosis as described by Agar is shown in 
Fig. 1; the second in Fig. 2. In the 'second' meiosis it can be seen that the chromosomes are reduced to short rounded nodules, and any supposition that they could break and exchange pieces of substance is obviously ludicrous.

But Agar's supposition that the same two partners could undergo meiotic pairing twice in the same ripening cycle is clearly incredible, and the account given by Dr. Walker unravels the mystery. By his researches, which were begun on the newt in his first paper and continued on several mammals in his second paper, he has proved conclusively that Agar's 'first meiosis' is not a meiosis at all but a belated ordinary division of the nucleus. This begins in the telophase of the preceding division of the sexual cell. When this division is complete and the daughter nuclei are passing into the resting phase, the telophase filaments can be seen to be split. In the resting phase this split disappears. But in the subsequent stage of activity, when long thin threads begin to be differentiated (the so-called leptotene stage), the split reappears and the separating chromosomes have been mistaken for meiotic partners. The pictures drawn by enthusiastic geneticists of long chromosomes with nodular thickenings opposite each other as proofs that similar 'genes' attract one another, are simply the expression of the division of moniliform chromosomes.

If, then, it is impossible to talk of 'genes' being in any particular chromosome-or of breaking and crossing over-it is difficult to see what remains of modern 'genetics'. As readers of NATURE are well aware, I am convinced that functional heredity, in other words, the handing on in some degree of habits acquired in one generation to the next, has been finally proved to be true, and this principle once admitted is sufficient to explain evolution and the origin of natural races and species. But the question of the origin, nature and inheritance of mutations, otherwise 'sports', remains to be dealt with. On this subject a great deal of light has been thrown by Prof. Mohr, of the University of Oslo, in a paper entitled "Über Letalfaktoren mit Berüksichtigung ihres Verhaltens bei Haustieren und beim Menschen" (Zeitschrift für induktive Abstammungsund Vererbungslehre, 41 ; 1926). He shows that in Drosophila and in other forms an astounding number of mutations are what he terms 'lethal' or 'sub-lethal'. In Drosophila, the so-called 'modifying' factors which by themselves produce no outward visible effect and indeed whose existence is assumed in order to force the facts into the Morgan scheme, produce no effect on the viability of the insect. These he places in fanciful comparison at the red end of the spectrum. As we pass towards the yellow and green we encounter mutations which make a marked difference in the appearance of the insect, and these decrease the viability until in the blue we encounter the sublethal mutations which injure their carriers so much that they can only be reared in a cross with a normal form. We finally reach the lethal factors in the violet, which even in a cross cause the death of their carriers. He shows further that such mutations are distributed over all the chromosomes and that new lethal factors are continually coming into being.

The obvious conclusion is that all mutations are of the physiological nature of damage to the growing powers of the germ, and when we consider the known artificial means of producing mutations, such as X-rays, heat, etc., applied to the eggs, this conclusion is so clear as scarcely to require statement. These agents kill the majority of eggs subjected to their influence: some resist them unaltered and some are half-killed and grow up to produce the mutations. Beneficent mutations which could survive in the struggle for existence are figments of the imagination.

Johannsen's demonstration that in a 'pure line' fluctuating variations are non-heritable marks one of the great advances in evolutionary knowledge, for it destroyed the basal assumption of the classical Darwinian theory that heritable variations in all directions are constantly occurring, some of which may chance to fit the environment and so be preserved. It was he who invented the term 'gene' as the cause of a mutation. About this word he says ("Some Remarks about Heredity," Hereditas, 4, 1923): "I introduced the word 'gene' when I was possessed by the antiquated spirit shown in Galton's, Weismann's and Mendel's viewpoints. Here we shall try to exterminate in genetics the term 'unit-character' because it indicates a notion inadequate and noxious for genetics. The most important part of the genotype does not seem able to segregate into units; as yet we are operating with characters which are superficial in comparison with the fundamental specific organic nature of the organism. However we try to analyse a genotype into factors we must remember that the characters of the organism, that is, its phenotypical features, are the reaction of the genotype in toto. Mendelian units per se are powerless. Are the experimentally demonstrated units anything more than expressions for local deviations from the original normal state of the chromosomes? The Weismannian distinction between germ-plasm and soma, that is, absolute independence, does not exist in reality. 'Gene' has nothing to do with De Vries's expression 'Pangenes' and their behaviour as units; the phenotype is the reaction of the genotype (nature) with the ambient conditions (nurture)." 